\title{
PERTUMBUHAN DAN HASIL TANAMAN TOMAT (Lycopersicum esculentum Mill) PADA BERBAGAI JENIS MULSA
}

\section{GROWTH AND RESULTS OF TOMATO PLANTS (Lycopersicum esculentum Mill) ON VARIOUS TYPES OF MULSES}

\author{
Darmo Asamin ${ }^{1}$, Hasmari Noer ${ }^{1 *}$, Sayani $^{1}$ \\ ${ }^{1}$ Program Studi Agroteknologi, Fakultas Pertanian Universitas Alkhairaat Palu, \\ Jl. Diponegoro No. 39 Palu 94221, Indonesia
}

\begin{abstract}
ABSTRAK
Penelitian ini bertujuan untuk mengetahui dan mempelari pertumbuhan dan hasil tanaman tomat pada berbagai jenis mulsa yang dilaksanakan di Desa Maku Kecamatan Biromaru Kabupaten Sigi Provinsi Sulawesi Tengah. Penelitian ini dirancang dengan menggunakan Rancangan Acak Kelompok (RAK) satu faktor yang dikelompokkan berdasarkan tinggi bibit tanaman. Perlakuan yang dicobakan berbagi jenis mulsa (M), Adapun perlakuan penelitian sebagai berikut: tanpa mulsa, mulsa plastik perak hitam, mulsa plastik trasparan, 10 t/ha serbuk gergaji kayu dan 10 t/ha jerami padi. Setiap perlakuan diulang sebanyak tiga kali ulangan sehingga terdapat 15 petak percobaan. Untuk mengetahui pengaruh perlakuan yang dicobakan maka dilakukan analisis ragam 0,05. Analisis ragam yang menunjukkan pengaruh nyata, dilakukan uji lanjut BNJ $\alpha=0,05$. Hasil penelitian meunjukkan bahwa penggunaan berbagai jenis mulsa berpengaruh nyata terhadap pertumbuhan dan hasil tanaman tomat. Mulsa jerami 10 t/ha memberikan rata-rata pertumbuhan dan hasil tanaman tomat yang lebih baik, berturut-turut; tinggi tanaman tomat umur 3 dan 6 MST sebesar $34,37 \mathrm{~cm}$ dan 70,27 cm, diameter batang umur 3 dan 6 MST sebesar 2,31 mm dan 2,41 mm, jumlah cabang umur 3 dan 6 MST sebesar 0,60 buah dan 5,80 buah, hasil panen I, II dan III masing-masing sebesar $0,93 \mathrm{~kg} /$ petak, $0,99 \mathrm{~kg} /$ petak dan $1,79 \mathrm{~kg} /$ petak, hasil total panen per petak sebesar 3,70 kg/petak dan hasil panen perhektar sebesar 6,17 t/ha.
\end{abstract}

Katakunci: mulsa, tomat, pertumbuhan dan hasil

\section{ABSTRACT}

This study aims to determine and explore the growth and yield of tomato plants in various types of mulch carried out in Maku Village, Biromaru District, Sigi Regency, Central Sulawesi Province. This study was designed using a randomized block design (RAK) of one factor grouped based on plant seed height. The treatment that was tried was to share the type of mulch $(M)$, the treatment of the study was as follows: without mulch, black silver plastic mulch, transparent plastic mulch, $10 \mathrm{t} / \mathrm{ha}$ wood sawdust and $10 \mathrm{t} / \mathrm{ha}$ rice straw. Each treatment was repeated three times so that there were 15 experimental plots. To find out the effect of the treatment being tried, a variance analysis of 0.05 was carried out. Analysis of variance that showed a significant effect, carried out further tests BNJ $\alpha=0.05$. The results of the study showed that the use of various types of mulch had a significant effect on the growth and yield of tomato plants. $10 \mathrm{t} / \mathrm{ha}$ straw mulch gives better growth rates and yields of tomato plants, respectively; the height of tomato plants aged 3 and 6 MST was $34.37 \mathrm{~cm}$ and $70.27 \mathrm{~cm}$, stem diameters of 3 and 6 weeks were $2.31 \mathrm{~mm}$ and $2.41 \mathrm{~mm}$, the number of branches aged 3 and $6 \mathrm{MST}$ was 0.60 and 5.80 pieces, yields I, II and III were $0.93 \mathrm{~kg} /$ plot, $0.99 \mathrm{~kg} /$ plot and $1.79 \mathrm{~kg} /$ plot respectively, the total yield per plot was $3.70 \mathrm{~kg} /$ plot and Harvest yield per hectare is $6.17 \mathrm{t} / \mathrm{ha}$.

Keywords: mulses, tomato, growth and results

\section{Pendahuluan}

Tomat (Lycopersicum esculentum Mill.) merupakan sayuran dan buah yang tergolong tanaman semusim berbentuk perdu dan

\footnotetext{
${ }^{*)}$ Penulis Korespondensi

E-mail: hasmarinoer7@gmail.com

Telp: $+62-8122134908$
}

termasuk dalam famili Solanaceae. Buahnya merupakan sumber vitamin dan mineral. Pemanfatan tanaman tomat semakin luas, karena selain di konsumsi sebagai tomat segar dan untuk bumbu masakan, juga dapat di olah lebih lanjut sebagai bahan baku industri 


\section{Jurnal Ozrotech 9 (1) 1-6}

makanan seperti sari buah dan saus tomat (Solfiyeni $d k k .$, 2011).

Produktivitas tanaman tomat ditentukan oleh tujuh (7) faktor lingkungan, yaitu : (1) cahaya, (2) bantuan mekanik (pengolahan tanah dan ajir), (3) suhu, (4) udara, (5) air, (6) unsur hara serta (7) keberdaaan organisme pengganggu tanaman (OPT) (Wang, 2000). Untuk itu, diperlukan suatu upaya pengelolaan tanaman agar faktor-faktor lingkungan tersebut optimal bagi pertumbuhan dan perkembangan tanaman.

Menurut Evans and Thurnbull (2007) bahwa mulsa adalah suatu material yang diletakkan di sekitar tanaman/pohon untuk menekan gulma dengan cara berat fisik (physical weight) dan menghalangi sinar matahari dan mempunyai keuntungan tambahan berupa berkurangnya kehilangan air dari permukaan tanah. Lebih lanjut dikatakan bahwa pemulsaan (mulching) biasanya terlalu mahal untuk tanaman skala besar, tapi merupakan metode pemberantasan gulma yang ideal pada tanaman di desa, di mana bahan-bahan seperti daun, kulit, batu tersedia. Pada tanaman yang pertumbuhan gulmanya sangat cepat, pemberian mulsa sering tidak berhasil. Berdasarkan uraian di atas, maka dilakukan suatu penelitian tentang pertumbuhan dan hasil tanaman tomat pada berbagai jenis mulsa.

\section{Metode Penelitian}

Penelitian ini dirancang dengan menggunakan Rancangan Acak Kelompok (RAK) satu faktor yang dikelompokkan berdasarkan tinggi bibit tanaman. Perlakuan yang dicobakan berbagi jenis mulsa (M), untuk mulsa organik ditentukan berdasarkan hasil penelitian (Samiati, 2012). Adapun perlakuan penelitian sebagai berikut:

Mo = tanpa mulsa

$\mathrm{M}_{1}=$ Mulsa plastik perak hitam

$\mathrm{M}_{2}=$ mulsa plastik transparan

$M_{3}=10$ t/ha serbuk gergaji kayu

$\mathrm{M}_{4}=10 \mathrm{t} / \mathrm{ha}$ jerami padi

Setiap perlakuan diulang sebanyak tiga kali ulangan sehingga terdapat 15 petak percobaan. Untuk mengetahui pengaruh perlakuan yang dicobakan maka dilakukan analisis ragam 0,05 . Analisis ragam yang menunjukkan pengaruh nyata, dilakukan uji lanjut BNJ $\alpha=0,05$ (Hanafiah, 2007).
e-ISSN : 2621-7236

p-ISSN : 1858-134X

\section{Pelaksanaan}

\section{Persiapan}

Jerami padi, serbuk gergaji, bahan kering tanaman kacang tanah dan pelepah daun kelapa serta pupuk kandang sapi diperoleh di sekitar lokasi penelitian. Benih tomat yang digunakan adalah varietas unggul, diperoleh dari Toko Tani di Kota Palu. Pupuk NPK majemuk dan benih tomat kemudian disemaikan pada petak persamaian $40 \mathrm{~cm}$ x $40 \mathrm{~cm}$ dengan mangatur jarak antar benih $3 \mathrm{~cm}$ sehingga terdapat 600 benih tomat. Petak persemaian kemudian dinaungi dengan menggunakan pelapah daun kelapa untuk mencegah penerimaan sinar matahari langsung yang dapat menghambat pertumbuhan bibit.

Bibit tomat dapat dipindahkan petak percobaan setelah berumur 15 hari di persemaian. Pada saat dilakukan penanaman petak percobaan, sebaiknya dilakukan lagi sortasi terhadap bibitbibit yang telah berumur 15 hari agar diperoleh tanaman yang baik pertumbuhannya dan memiliki daya produktivitas tinggi dalam menghasilkan buah. Untuk itu, dipilih dengan penampilan menarik dan baik, yaitu penampakannya segar dan daun-daunnya tidak rusak, dipilih bibit yang kuat, yaitu tegak pertumbuhannya dan dipilih bibit yang sehat, artinya bibit tidak terserang hama dan penyakit (Rukmana, 2004), kemudian bibit dikelompokkan menjadi tiga berdasarkan tingginya.

Pengolahan tanah dan pemupukan dasar

Pengolahan lahan dilakukan untuk memberikan kondisi lahan sebaik mungkin untuk pertumbuhan tanaman tomat. Pengolahan tanah dilakukan dengan mengunakan bajak singkal yang ditarik dengan ternak, kemudian diratakan dengan menggunakan garu yang ditarik dengan ternak, cangkul dan sekop. Setelah itu dilakukan dengan pembuatan petak percobaan dengan ukuran $200 \mathrm{~cm}$ x $300 \mathrm{~cm}$ dan jarak antar petak percobaan $40 \mathrm{~cm}$.

Pemupukan dasar dilakukan setelah terbentuk petak percobaan, pupuk kandang sapi diberikan pada setiap petak percobaan dengan dosis $10 \mathrm{t} / \mathrm{ha}$ atau setara dengan $6 \mathrm{~kg} /$ petak.

\section{Penanaman}

Penanaman dilakukan dengan membuat lubang tanam sedalam $\pm 5 \mathrm{~cm}$, selanjutnya meletakkan bibit tomat dengan hati-hati agar batang tanaman tidak patah. Kemudian menimbun kembali agar bibit tumbuh tegak. 


\section{Jurnal Agrotech 9 (1) 1-6}

Setelah itu diberikan naungan pelepah pisang, jarak tanam yang diterapkan adalah $40 \mathrm{~cm}$ x $50 \mathrm{~cm}$, sehingga terdapat 25 populasi tanaman tomat per petak.

\section{Pemeliharaan}

Pengairan dilakukan setiap pagi hari dengan pertimbangan lahan tanaman mencapai kapasitas lapang yang diindikasikan dengan permukaan atas lahan sudah kelihatan basah. Penyiangan dilakukan dengan membersihkan gulma agar tidak terjadi kompetisi dengan tanaman pokok dan dilakukan penggemburan agar dapat mempermudah pertumbuhan dan perkembangan akar tanaman tomat.

Pemupukan dilakukan dengan menggunakan pupuk granular NPK majemuk dengan dosis $10 \mathrm{~g} / \mathrm{tanaman}$, diaplikasikan dengan cara melarutkan 250 g pupuk NPK majemuk dalam 5 liter air, kemudian disiramkan 250 $\mathrm{ml} /$ tanaman dalam setip petak percobaan, pemupukan dilakukan saat tanaman tomat berumur 10 hari setelah tanam (HST).

Pemasangan ajir dimaksudkan untuk mencegah tanaman tomat roboh. Hal-hal yang perlu diperhatikan: Ajir (lanjaran) terbuat dari bambu dengan panjang $175 \mathrm{~cm}$. Cara memasang ajir dibuat tegak lurus, agar tidak dimakan rayap, ajir. Tanaman tomat yang telah mencapai ketinggian $15 \mathrm{~cm}$, segera diikat pada ajir. Pengikatan jangan terlalu erat yang penting tanaman tomat dapat berdiri. Pengikatan dilakukan dengan model angka 8 sehingga tidak terjadi gesekan antara batang tomat dengan ajir yang dapat menimbulkan luka. Tali pengikat yang digunakan adalah tali plastik dalam keadaan bersih. Setiap bertambah tinggi $\pm 20 \mathrm{~cm}$, harus dilakukan pengikatan lagi agar batang tomat selalu berdiri tegak.

\section{Aplikasi perlakuan}

$\mathrm{M}_{1}=$ mulsa plastik perak hitam (MPPH), diplikasikan sebelum tanam dengan cara menempatkan di atas permukaan lahan (Lampiran 1), selanjutnya dilubangi menggunakan gunting sesuai jarak tanam.

$\mathrm{M}_{2}=$ mulsa plastik transparan, diplikasikan sebelum tanam dengan cara menempatkan di atas permukaan lahan (Lampiran 1), selanjutnya dilubangi menggunakan gunting sesuai jarak tanam

$\mathbf{M}_{3}=10 \mathrm{t} / \mathrm{ha}$ serbuk gergaji kayu atau setara dengan $6 \mathrm{~kg} /$ petak, diaplikasikan 1 minggu setelah tanam (MST) dengan cara menebar serbuk gergaji kayu disekitar tanaman tomat.
e-ISSN : 2621-7236

p-ISSN : 1858-134X

$\mathrm{M}_{4}=10 \mathrm{t} / \mathrm{ha}$ jerami padi atau setara dengan 6 $\mathrm{kg} /$ petak, diaplikasikan 1 minggu setelah tanam (MST) dengan cara menebar mulsa jerami disekitar tanaman tomat.

\section{Panen}

Pemetikan buah atau panen pertama dilakukan pada saat tanaman tomat telah berumur 72 hari setelah tanam (HST). Kriteria masak petik yang optimal dapat dilihat dari warna kulit buah, ukuran buah, keadaan daun tanaman dan batang tanaman, yakni sebagai berikut : a) kulit buah berubah, dari warna hijau menjadi kekuning-kekuningan, b) bagian tepi daun tua telah mengering, c) batang tanaman menguning/mengering.

\section{Parameter Pengamatan}

Untuk mengetahui pengaruh perlakuan yang diteliti, maka diamati variabel komponen pertumbuhan dan hasil tanaman tomat, yang meliputi:

1. Tinggi tanaman $(\mathrm{cm})$, mengukur $2 \mathrm{~cm}$ dari permukaan media tumbuh hingga titik tumbuh tanaman tomat. Pengukuran dilakukan pada 5 tanaman sampel yang telah ditentukan secara diagonal saat berumur 3 dan 6 MST.

2. Diameter batang $(\mathrm{mm})$, pengamatan diameter batang dilakukan dengan menggunakan jangka sorong, pada 5 tanaman sampel yang telah ditentukan secara diagonal saat berumur 3 dan 6 MST.

3. Jumlah cabang (helai), dilakukan dengan cara menghitung cabang tanaman tomat, dilakukan pada 5 tanaman sampel yang telah ditentukan secara diagonal saat berumur 3 dan 6 MST.

4. Hasil panen I, II dan III

Hasil panen I, II, dan III adalah total bobot buah tomat yang diperoleh pada masingmasing waktu pelaksanaan panen I, II dan III pada setiap petak percobaan.

5. Rerata hasil per petak (kg/petak), dilakukan dengan cara menimbang buah tanaman yang diperoleh setiap panen pada tiap petak percobaan hingga panen terakhir (umur tanaman 12 MST), selanjutnya dijumlahkan keseluruhannya.

6. Rerata hasil per hektar (t/ha), dilakukan dengan mengkonversi hasil per petak (kg/petak) ke hasil per hektar (t/ha), melalui persamaan:

Hasil per hektar $\quad(\mathrm{t} / \mathrm{ha}) \quad=$
$\frac{\text { hasil per petak }(\mathrm{kg}) \times 10.000 \mathrm{~m}^{2}}{\text { luas petak } \mathrm{m}^{2} \times 1.000(\mathrm{~kg})}$




\section{Hasil}

Tinggi tanaman

Hasil analisis ragam menunjukkan bahwa perlakuan berbagai jenis mulsa berpengaruh nyata terhadap tinggi tanaman tomat pada umur 3 MST sedangkan saat tanaman tomat berumur 6 MST berpengaruh tidak nyata. Adapun rata-rata tinggi tanaman tomat saat berumur 3 dan 6 MST pada perlakuan berbagai jenis mulsa disajikan pada Tabel 1.

\begin{tabular}{|c|c|c|}
\hline \multirow[t]{2}{*}{ Perlakuan } & \multicolumn{2}{|c|}{$\begin{array}{l}\text { Tinggi tanaman } \\
(\mathrm{cm}) \text { tomat: }\end{array}$} \\
\hline & $3 \mathrm{MST}$ & $6 \mathrm{MST}$ \\
\hline Mo $=$ tanpa mulsa & $27,60 \mathrm{~b}$ & 68,33 \\
\hline $\mathrm{M}_{1}=$ Mulsa plastik PM & $25,87 \mathrm{~b}$ & 60,13 \\
\hline $\mathrm{M}_{2}=$ mulsa plastik Trans & $22,30 \mathrm{~b}$ & 61,27 \\
\hline$M_{3}=$ serbuk gergaji kayu & $34,73 \mathrm{a}$ & 72,20 \\
\hline $\mathrm{M}_{4}=$ jerami padi & $34,37 \mathrm{a}$ & 70,27 \\
\hline BNT $\alpha=0,05$ & 4,76 & - \\
\hline
\end{tabular}

Keterangan : angka-angka yang diikuti dengan huruf sama pada kolom sama menunjukkan pengaruh berbeda tidak nyata pada taraf uji BNT $\alpha=0,05$

Tabel 1 menunjukkan bahwa perlakuan mulsa serbuk gergaji kayu (M3) memberikan rata-rata tinggi tanaman tomat saat berumur 3 MST tertinggi sebesar $34,73 \mathrm{~cm}$ berbeda tidak nyata dengan mulsa jerami padi (M4), namun berbeda nyata dengan perlakuan tanpa mulsa, mulsa plastik PM dan mulsa plastik transparan.

Diameter batang

Hasil analisis ragam menunjukkan bahwa perlakuan berbagai jenis mulsa berpengaruh nyata terhadap diameter batang tanaman tomat pada umur 3 MST dan 6 MST. Adapun rata-rata diameter batang tanaman tomat saat berumur 3 dan 6 MST pada perlakuan berbagai jenis mulsa disajikan pada Tabel 2.

Tabel 2 menunjukkan bahwa perlakuan mulsa jerami padi (M4) memberikan rata-rata diameter batang tanaman tomat saat berumur 3 dan 6 MST terbaik sebesar 2,13 mm dan 2,41 $\mathrm{mm}$ berbeda tidak nyata dengan mulsa serbuk gergaji kayu (M3), namun berbeda nyata dengan perlakuan tanpa mulsa, mulsa plastik PM dan mulsa plastik transparan.
Tabel 2. Diameter batang tanaman tomat saat berumur 3 dan 6 MST pada perlakuan berbagai jenis mulsa

\begin{tabular}{|c|c|c|}
\hline \multirow[t]{2}{*}{ Perlakuan } & \multicolumn{2}{|c|}{$\begin{array}{l}\text { Diameter batang } \\
(\mathrm{mm}) \text { tanaman } \\
\text { tomat: }\end{array}$} \\
\hline & $3 \mathrm{MST}$ & $6 \mathrm{MST}$ \\
\hline Mo = tanpa mulsa & $0,47 \mathrm{~b}$ & $1,46 \mathrm{bc}$ \\
\hline $\mathrm{M}_{1}=$ Mulsa plastik PM & $0,25 \mathrm{~b}$ & $1,48 \mathrm{bc}$ \\
\hline $\mathbf{M}_{2}=$ mulsa plastik Trans & $0,19 \mathrm{~b}$ & $0,97 \mathrm{c}$ \\
\hline$M_{3}=$ serbuk gergaji kayu & $1,66 \mathrm{a}$ & $2,35 \mathrm{ab}$ \\
\hline $\mathbf{M}_{4}=$ jerami padi & $2,13 \mathrm{a}$ & $2,41 \mathrm{a}$ \\
\hline BNT $\alpha=0,05$ & 0,62 & 0,91 \\
\hline
\end{tabular}

Keterangan : angka-angka yang diikuti dengan huruf sama pada kolom sama menunjukkan pengaruh berbeda tidak nyata pada taraf uji BNT $\alpha=0,05$

Jumlah cabang

Hasil analisis ragam menunjukkan bahwa perlakuan berbagai jenis mulsa berpengaruh nyata terhadap jumlah cabang tanaman tomat pada umur 6 MST. Adapun rata-rata jumlah cabang tanaman tomat saat berumur 3 dan 6 MST pada perlakuan berbagai jenis mulsa disajikan pada Tabel 3.

Tabel 3. Jumlah cabang tanaman tomat saat berumur 3 dan 6 MST pada perlakuan berbagai jenis mulsa

\begin{tabular}{|c|c|c|}
\hline \multirow[t]{2}{*}{ Perlakuan } & \multicolumn{2}{|c|}{$\begin{array}{l}\text { Jumlah cabang } \\
\text { tanaman tomat : }\end{array}$} \\
\hline & $3 \mathrm{MST}$ & $6 \mathrm{MST}$ \\
\hline Mo = tanpa mulsa & 0,27 & $4,00 \mathrm{~b}$ \\
\hline $\mathrm{M}_{1}=$ Mulsa plastik PM & 0.00 & $3,73 \mathrm{bc}$ \\
\hline $\mathbf{M}_{2}=$ mulsa plastik Trans & 0,20 & $3,13 \mathrm{c}$ \\
\hline $\mathrm{M}_{3}=$ serbuk gergaji kayu & 0,93 & $5,27 \mathrm{a}$ \\
\hline$M_{4}=$ jerami padi & 0,60 & $5,80 \mathrm{a}$ \\
\hline BNT $\alpha=0,05$ & - & 0,62 \\
\hline
\end{tabular}

Keterangan : angka-angka yang diikuti dengan huruf sama pada kolom sama menunjukkan pengaruh berbeda tidak nyata pada taraf uji BNT $\alpha=0,05$

Tabel 3 menunjukkan bahwa perlakuan mulsa jerami padi (M4) memberikan rata-rata jumlah cabang tanaman tomat saat berumur 6 MST terbaik sebesar 5,80 buah berbeda tidak nyata dengan mulsa serbuk gergaji kayu (M3), namun berbeda nyata dengan perlakuan tanpa mulsa, mulsa plastik PM dan mulsa plastik transparan. 


\section{Jurnal Ozrotech 9 (1) 1-6}

Hasil panen I, II dan III

Hasil analisis ragam menunjukkan bahwa perlakuan berbagai jenis mulsa berpengaruh nyata terhadap hasil panen I tanaman tomat. Adapun rata-rata hasil panen I, II dan III tanaman tomat pada perlakuan berbagai jenis mulsa disajikan pada Tabel 4.

Tabel 4. Hasil panen I, II dan III tanaman tomat pada perlakuan berbagai jenis mulsa

\begin{tabular}{|c|c|c|c|}
\hline \multirow{2}{*}{ Perlakuan } & \multicolumn{3}{|c|}{ Hasil Panen (kg/Petak) : } \\
\hline & I & II & III \\
\hline Mo $=$ tanpa mulsa & $0,69 \mathrm{bc}$ & 0,63 & 0,89 \\
\hline $\begin{array}{ll}\mathrm{M}_{1} \quad= & \text { Mulsa } \\
\text { plastik PM } & \end{array}$ & $0,80 \mathrm{ab}$ & 0,71 & 1,50 \\
\hline $\begin{array}{l}\mathrm{M}_{2}=\text { mulsa } \\
\text { plastik Trans }\end{array}$ & $0,61 \mathrm{c}$ & 0,76 & 1,07 \\
\hline $\begin{array}{l}\mathrm{M}_{3}=\text { serbuk } \\
\text { gergaji kayu }\end{array}$ & $0,86 \mathrm{ab}$ & 0,80 & 1,76 \\
\hline $\mathrm{M}_{4}=$ jerami padi & 0,93 a & 0,99 & 1,79 \\
\hline BNT $\alpha=0,05$ & $\mathbf{0 , 1 7}$ & & \\
\hline
\end{tabular}

Keterangan : angka-angka yang diikuti dengan huruf sama pada kolom sama menunjukkan pengaruh berbeda tidak nyata pada taraf uji BNT $\alpha=0,05$

Tabel 4 menunjukkan bahwa perlakuan mulsa jerami padi (M4) memberikan rata-rata hasil panen I tanaman tomat terbaik sebesar 0,99 $\mathrm{kg} /$ petak berbeda tidak nyata dengan mulsa serbuk gergaji kayu (M3) dan mulsa plastik PM, namun berbeda nyata dengan perlakuan tanpa mulsa dan mulsa plastik transparan.

Hasil total panen per petak

Hasil analisis ragam menunjukkan bahwa perlakuan berbagai jenis mulsa berpengaruh nyata terhadap hasil total panen per petak tanaman tomat. Adapun rata-rata hasil total panen per petak tanaman tomat pada perlakuan berbagai jenis mulsa disajikan pada Tabel 5.

Tabel 5. Hasil total panen per petak tanaman tomat pada perlakuan berbagai jenis mulsa

\begin{tabular}{lc}
\hline Perlakuan & $\begin{array}{c}\text { Hasil panen } \\
(\mathbf{k g} / \text { petak })\end{array}$ \\
\hline Mo $=$ tanpa mulsa & $2,22 \mathrm{c}$ \\
$\mathrm{M}_{1}=$ Mulsa plastik PM & $3,00 \mathrm{abc}$ \\
$\mathrm{M}_{2}=$ mulsa plastik Trans & $2,44 \mathrm{bc}$ \\
$\mathrm{M}_{3}=$ serbuk gergaji kayu & $3,42 \mathrm{ab}$ \\
$\mathrm{M}_{4}=$ jerami padi & $3,70 \mathrm{a}$ \\
\hline BNT $\alpha=0,05$ & 0,98
\end{tabular}

Keterangan : angka-angka yang diikuti dengan huruf sama pada kolom sama menunjukkan pengaruh berbeda tidak nyata pada taraf uji BNT $\alpha=0,05$
e-ISSN : 2621-7236

p-ISSN : 1858-134X

Tabel 5 menunjukkan bahwa perlakuan mulsa jerami padi (M4) memberikan rata-rata hasil total panen per petak tanaman tomat terbaik sebesar $3,70 \mathrm{~kg} /$ petak berbeda tidak nyata dengan mulsa serbuk gergaji kayu (M3) dan mulsa plastik PM, namun berbeda nyata dengan perlakuan tanpa mulsa dan mulsa plastik transparan.

Hasil panen per hektar

Hasil analisis ragam menunjukkan bahwa perlakuan berbagai jenis mulsa berpengaruh nyata terhadap hasil panen per hektar tanaman tomat. Adapun rata-rata hasil panen per hektar tanaman tomat pada perlakuan berbagai jenis mulsa disajikan pada Tabel 6 .

Tabel 6. Hasil total panen per petak tanaman tomat pada perlakuan berbagai jenis mulsa

\begin{tabular}{lc}
\hline Perlakuan & $\begin{array}{c}\text { Hasil total } \\
\text { panen tanaman } \\
\text { tomat }(\mathbf{t} / \mathbf{h a})\end{array}$ \\
\hline $\mathrm{Mo}=$ tanpa mulsa & $3,69 \mathrm{c}$ \\
$\mathrm{M}_{1}=$ Mulsa plastik PM & $5,00 \mathrm{abc}$ \\
$\mathrm{M}_{2}=$ mulsa plastik Trans & $4,07 \mathrm{bc}$ \\
$\mathrm{M}_{3}=$ serbuk gergaji kayu & $5,70 \mathrm{ab}$ \\
$\mathrm{M}_{4}=$ jerami padi & $6,17 \mathrm{a}$ \\
\hline $\mathrm{BNT} \alpha=0,05$ & 1,63 \\
\hline
\end{tabular}

Keterangan : angka-angka yang diikuti dengan huruf sama pada kolom sama menunjukkan pengaruh berbeda tidak nyata pada taraf uji BNT $\alpha=0,05$

Tabel 6 menunjukkan bahwa perlakuan mulsa jerami padi (M4) memberikan rata-rata hasil total panen per petak tanaman tomat terbaik sebesar 6,17 t/ha berbeda tidak nyata dengan mulsa serbuk gergaji kayu (M3) dan mulsa plastik PM, namun berbeda nyata dengan perlakuan tanpa mulsa dan mulsa plastik transparan.

\section{Pembahasan}

Berdasarkan hasil penelitian menunjukkan bahwa perlakuan berbagai jenis mulsa berpengaruh nyata terhadap pertumbuhan dan hasil tanaman tomat. Jenis mulsa berpengaruh terhadap pertumbuhan dan hasil tanaman tomat, terutama pada pengamatan tinggi tanaman pada umur 3 MST, diameter batang pada umur 3 dan 6 MST, jumlah cabang pada umur 6 MST, hasil panen I, hasil total panen per petak dan hasil panen tanaman tomat per hektar.

Jenis gulma yang diaplikasikan dalam pelaksanaan penelitian ini (mulsa plastik perak 


\section{Jurnal Ozrotech 9 (1) 1-6}

hitam, mulsa plastik transparan, mulsa serbuk gergaji kayu dan mulsa jerami padi) telah dilakukan oleh peneliti terdahulu dengan lokasi dan komoditi yang berbeda. Hasil penelitian menunjukkan bahwa mulsa jerami padi memberikan rata-rata pertumbuhan dan hasil tanaman tomat yang lebih baik dibandingkan dengan tanpa pemulsaan, mulsa plastik transparan, mulsa plastik perak hitam dan mulsa serbuk gergaji di Desa Maku Kecamatan Biromaru Kabupaten Sigi.

Mulsa organik, anorganik dan kimia sentitis berperan dalam mengendalikan fruktuasi suhu tanah, menekan pertumbuhan dan perkembangan gulma dan terpaan air hujan agar tidak terjadi erosi permukaan tanah (run off) (Umbo, 1997; Evans and Thurnbull, 2007; Effendi, 2010). Namun hasil penelitian menunjukkan bahwa mulsa jerami (M4) memberikan pertumbuhan dan hasil tanaman tomat yang lebih baik. Hal ini diduga karena mulsa jerami padi, selain memiliki peran sebagai mulsa juga dapat menambah kesuburan tanah dan meningkatkan aktivitas mikroorganisme dalam tanah dalam merombak bahan organik (jerami padi).

Hasil penelitian menunjukkan bahwa mulsa jerami padi dengan musla serbuk gergaji memberikan pertumbuhan dan hasil tanaman tomat yang berbeda tidak nyata. Hal ini menggambarkan bahwa mulsa organik dapat meningkatkan kesuburan tanah, seperti dikemukaan oleh Pujisiswanto (2011) bahwa mulsa dapat menghambat masuknya sinar matahari dan pertumbuhan gulma. Mulsa alami termasuk jerami dan rumput-rumputan memiliki manfaat lain dengan menambahkan bahan organik dan nutrisi ke tanah.

\section{Kesimpulan dan Saran}

\section{Kesimpulan}

Berdasarkan hasil dan pembahasan tentang pertumbuhan dan hasil tanaman tomat pada berbagai jenis mulsa, dapat disimpulkan bahwa mulsa jerami $10 \mathrm{t} / \mathrm{ha}$ memberikan rata-rata pertumbuhan dan hasil tanaman tomat yang lebih baik, berturut-turut; tinggi tanaman tomat umur 3 dan 6 MST sebesar $34,37 \mathrm{~cm}$ dan $70,27 \mathrm{~cm}$, diameter batang umur 3 dan 6 MST sebesar 2,31 $\mathrm{mm}$ dan 2,41 $\mathrm{mm}$, jumlah cabang umur 3 dan 6 MST sebesar 0,60 buah dan 5,80 buah, hasil panen I, II dan III masing-masing sebesar 0,93 $\mathrm{kg} /$ petak, $0,99 \mathrm{~kg} /$ petak dan $1,79 \mathrm{~kg} /$ petak, hasil
e-ISSN : 2621-7236

p-ISSN : 1858-134X

total panen per petak sebesar $3,70 \mathrm{~kg} /$ petak dan hasil panen pe rhektar sebesar 6,17 t/ha.

\section{Saran}

Agar dilakukan penelitian lanjutan dengan mengkombinasikan mulsa organik dan penggunaan pupuk cair organik.

\section{Daftar Pustaka}

Effendi, R. 2007. Kemungkinan Penggunaan Mulsa Plastik Perak Hitam (MPPH) pada Pemeliharaan Hutan Tanaman. Mitra Hutan Tanaman Vol.2 No. 1. Puslitbang Hutan Tanaman Bogor.

Evan, J and J.E. Thunbull. 2007. Plantation Forestry in the Tropics. The Role, Silviculture, and Use of Planted Forests for Industrial, Social, Environment, and Agroforestry Purposes. Third Edition. Oxford University Press, UK.

Hanafiah, K.A., 2007. Rancangan Percobaan, Teori dan Aplikasi. Fakultas Pertanian Universitas Sriwijaya. Palembang

Pujisiswanto, H, 2011. Pertumbuhan Gulma dan Hasil Tanaman pada Tumpangsari Selada dengan Tomat diaplikasi Mulsa Jerami. Jurnal Agrivigor 10(2): 139-147, JanuariApril 2011; ISSN 1412-2286

Samiati, Andi Bahrun, dan La Ode Safuan, 2012. Pengaruh Takaran Mulsa terhadap Pertumbuhan dan Produksi Sawi (Brassica juncea L.). Berkala Penelitian Agronomi Oktober 2012 Vol. 1 No. 2 Hal. 121-125

Solfiyeni, Fauziah Safitri, Zuhri Syam, 2011. Uji Mulsa Tithonia diversifolia A. Gray Terhadap Pertumbuhan Gulma dan Produksi Tanaman Tomat (Lycopersicum esculentum Mill). Prosiding Seminar Nasional Biologi Departemen Biologi FMIPA Universitas Sumatera Utara (editor : Salomo Hutahean, Syafrudin Ilyas, Suci Rahayu dan Kaniwa Berliani). USU press. Medan. P :742-749)

Umboh AH. 1997. Petunjuk Penggunaan Mulsa. Penebar Swadaya. Jakarta

Wang, C.Y., 2000. Physiological and Biochemical Response of Plant to Solar Radiations and Waters Stress. Horticulture Science J. 17(4) : 179-186 